\title{
A Co-Word Analysis on Policy of Business Incubator in Guangdong Province
}

\section{Mengyuan Wen}

The School of Business Administration, South China University of Technology, Guangzhou, China

Email: mengyuanwen@sina.com

How to cite this paper: Wen, M.Y. (2018) A Co-Word Analysis on Policy of Business Incubator in Guangdong Province. Open Journal of Business and Management, 6, 214-224. https://doi.org/10.4236/ojbm.2018.61015

Received: December 18, 2017

Accepted: January 27, 2018

Published: January 30, 2018

Copyright (C) 2018 by author and Scientific Research Publishing Inc. This work is licensed under the Creative Commons Attribution International License (CC BY 4.0).

http://creativecommons.org/licenses/by/4.0/ (c) (i) Open Access

\begin{abstract}
In China, government policy support is an important driving force for promoting the development of incubators. The rationality and effectiveness of policies are the key to guiding the development of incubators in the early stage. Research on incubator policies can help clarify the support methods and priorities of policies. This paper employs the bibliometrics method and follows a procedure of keyword extraction, co-wording and cluster analysis to analyze the system and structural characteristics of incubator policy. The research shows that the overall policy of incubator in Guangdong is mainly composed of four types of policies: Land support, taxation, financial support, investment and financing policies. The financial support is at the core of the incubator policy system and policy is mainly focused on the front chain of incubator development, encouraging the development of the number of incubators while at the same time the support for talents is weak and the effect of policy implementation is not supervised. On this basis, combined with the reality of the development of incubators, this paper puts forward opinions and suggestions for the formulation and adjustment of the incubator policy.
\end{abstract}

\section{Keywords}

Incubator Policy, Co-Word Analysis, Co-Word Clustering Analysis

\section{Introduction}

In 2014, Premier Li Keqiang put forward the policy of "mass innovation and multitudinous entrepreneurship". As the public service platform for fostering start-ups and transforming science and technology achievements, business incubator has become an important starting point for the government to implement "double-innovation". Business incubators, also known as high-tech start-up service centers, internationally known as business incubators, are a new 
type of socio-economic organization. Incubator originally refers to artificial hatching eggs specialized equipment. Later, the introduction of the economic field refers to the reduction of the number of start-up enterprises by providing support for the sharing of facilities, systems training and consulting, policies, financing, laws and marketing in research, development, production and operation of venues, communications, networks and offices venture risk and start-up costs, and improving the survival rate and success rate. Incubator ushered in a new round of development boom and as of the end of 2016, the number of incubators in China reached 3255, nearly doubling the number in 2014, ranking the highest in the world. According to the experience of incubators at home and abroad, the government plays a crucial role in the development of incubators. For example, as the birthplace of incubator, the United States started direct investment in incubators and established local laws in early 1980s to promote the development of incubators. In China, government established the first incubator, and according to the report of ii Media Research, state-owned incubators accounted for $28.4 \%$ of the total in 2016 , with funds mainly coming from government support. 2017 is the 30th anniversary of the development of China's incubator, and it is necessary to sort out and study the current status, support methods and rationality of the government incubator policy, and to provide theoretical support and direction for optimizing and improving the incubator policy.

In the present literature, research on incubator policy mainly includes the qualitative research, namely the interpretation of policy documents, scholars such as Wu Shouren [1], Qu Qunzhen [2] and Sun Dong [3] put forward policy suggestions by comparing the development history of incubators at home and abroad with experiences. Shi Yongfeng [4] took Hangzhou as an example to construct an incubator government incentive model and interpret incentive policies of incubator in Hangzhou; others analyzed the policies and performance of a particular type of incubator, and put forward relevant improvement suggestions for such policies, such as tax policy, government subsidy policy and so on. Cheng $\mathrm{Yu}$ [5], Cui Jingjing analyzed tax policy for the incubator conduction and incentive effects through empirical research methods, and concluded that tax incentives played an important role for the development of incubators and; Tai Deiyi, Liuwei and others explored the tax and government subsidies influences for incubators and startup through game theory model.

From present literature we can know that the researches on the incubator policy is still under the superficial level of analysis which is interpreted by the policy documents with strong subjective judgment, but the reliability and universality of its analysis results are weaker. Or those researches lack a holistic analysis; from those we can't fully understand the characteristics of the incubator policy, support priorities and so on. The number of incubators in Guangdong ranks first among all provinces in China with a large number of incubator policies and high quality, which is of reference to other provinces and cities; therefore, this article takes the Guangdong incubator policy text from 2000 to 2016 as the research object. On the basis of screening the policy text of incubator 
in Guangdong Province, this paper uses the method of co-word analysis in quantitative study of policy documents to research the overall structure of incubator policy in Guangdong Province. Co-word analysis in bibliometrics reflects the cohesive relationship between the co-keywords and thus reflects the cohesion structure between these words, and then grasps the focus the overall structure of the literature. The applicability of the method is confirmed by Law [6] and other scholars [7] who argue that "co-word analysis can not only be used as a tool to understand and describe hot topics and their interrelationships, but also to study policy." From the perspective of the policy, quantitative research on policy documents can complement pure philosophical thinking with scientific norms to avoid completely subjective judgments. The quantitative analysis method can minimize the subjectivity, uncertainty and fuzziness of the research, besides the simple quantitative statistical analysis of policies has also gradually transitioned to policy measurement and analysis based on the content of policy texts [8] to further tap the policy implications at the micro levels [9]. Quantitative analysis is the new direction of public policy research [10], and also the innovation of this article.

This thesis is divided into three parts. The first part will collect the supporting documents of Guangdong Province's incubator policy and extract policy keywords through intensive reading of the policy texts. The second part builds a co-word matrix on the extracted key words, conducts multidimensional scaling clustering analysis and expounds the clustering result and its connotation. The third part analyzes the causes and background of its reality according to the clustering results and puts forward policy suggestions.

\section{Policy Selection and Keyword Extraction}

\subsection{Policy Text Collection}

Policies can be mainly divided into laws, administrative regulations and departmental rules from the perspective of effectiveness level [11]. In order to ensure data completeness, eight key words, which covering different forms and names of incubator, are chosen to search and collect policy text, including "incubator", "nurseries", "accelerator", "Wework", "innovation park", "High-tech start-up service center", "hatching base", "science and technology park". The sources of the policy texts include pkulaw and the websites of the government of Guangdong Province and its immediate departments. The retrieval method is the keyword full-text search and the scope of the policy text is the provincial incubator policy text of Guangdong Province from 2000-2016 (Since 2000, the state has released a relatively complete programmatic document on business incubators).In order to ensure the representativeness of the analysis, the repeated, invalidated and unrelated policy texts were removed after reading the policy texts intensively, and 81 valid research texts were finalized.

As incubator is usually used as a public service platform that the government encourages innovation and entrepreneurship to promote the transformation of 
scientific and technological achievements, its supportive policies involve many kinds of policy types, such as science and technology policy, industrial policy and innovation and entrepreneurship policy. Apart from the special policy text, more policies are scattered in the relevant policy texts and clauses are more scattered. Therefore, in order to ensure the completeness and pertinence of policy analysis, this article takes the policy provisions as the analysis unit and pick out 181 policy terms highly relevant to the incubator from the 81 policy texts.

\subsection{Keyword Extraction}

On the basis of reading the relevant articles on policy interpretation and repeated reading on policy terms, we extracted policy keywords related to the incubator from the 181 policy terms. In the process of policy keyword extraction, in order to avoid scattered keywords, unable to achieve effective common-word analysis and accurate reflection of the policy content, this paper combines the three environmental policy tools theory by Rothwell and Zegveld [12], and select the key words mainly from the perspective of policy tools, as policy tool is the core of the policy and can reflect the policy focus, government's support priorities and ideas, which make the extraction more reasonable. In the end, 3 - 8 keywords are extracted from each policy text, and the similar keywords are merged and simplified. For example, "financial capital subsidies" and "business hatching subsidies" are consolidated into "financial subsidies". In order to be able to further converge the key words, the key words appearing below 2 are not taken into account. After keyword extraction and standardization, the final 31 keywords are got. As shown in Table 1.

\section{Data Analysis}

\subsection{Construct Co-Word Matrix}

The co-word matrix is a matrix which represent the occurrence frequency of a particular word pair in the same document [13], and is produced based on the number of occurrences of the same policy on each pair by bibexcel, a statistical software. According to the high-frequency keywords obtained in Table 1, the co-word matrices are sorted and generated. Part of the results are shown in Table 2, for example, financial subsidy and qualification have 20 simultaneous occurrences in different incubator support policy terms, the number in the two word correspondence tables is 20 .

For the next co-word clustering analysis, the co-word matrix needs to be further processed as a similarity matrix, which describes the correlation between word pairs. Since the co-word matrix has the meaning of a certain descriptor to the similarity, the similarity matrix is no longer transformed into a dissimilar matrix so as to reduce the degree of distortion of the data. The methods used to measure the similarity between variables mainly include Cosine similarity, Pearson correlation coefficient and Ochiai coefficient. The Pearson correlation coefficient is not suitable for sparse data sets and it has decentering function 
Table 1. Keyword frequency table of incubator policy.

\begin{tabular}{|c|c|c|c|c|c|}
\hline Encoding & Key word & Frequency & Encoding & Key word & Frequency \\
\hline D1 & Financial Subsidy & 38 & D17 & Rent Reduction & 8 \\
\hline $\mathrm{D} 2$ & Qualification & 32 & D18 & Financing Support & 7 \\
\hline D3 & Entrepreneurship and Employment & 31 & D19 & Government Purchases & 7 \\
\hline $\mathrm{D} 4$ & Achievement Transformation & 27 & D20 & Accelerate Depreciation & 7 \\
\hline D5 & $\begin{array}{c}\text { Industry university research } \\
\text { Cooperation }\end{array}$ & 25 & $\mathrm{D} 21$ & Industrial Land Reform & 6 \\
\hline D6 & Financial Incentive & 18 & D22 & Public Crowd funding & 5 \\
\hline D7 & Post-subsidy & 16 & D23 & Loan Discount & 5 \\
\hline D8 & $\begin{array}{l}\text { Scientific and Technological } \\
\text { Innovation }\end{array}$ & 16 & D24 & Angel Investment & 4 \\
\hline D9 & Special Funds & 13 & D25 & “Three Old" Transformation & 4 \\
\hline D10 & Demonstration base & 12 & D26 & Service Platform & 3 \\
\hline D11 & Performance Evaluation & 10 & $\mathrm{D} 27$ & Infrastructure Construction & 3 \\
\hline D12 & Tax Preference & 10 & D28 & R\&D Costs Deduction & 3 \\
\hline D13 & Land Use Planning & 10 & D29 & Property Separating & 2 \\
\hline D14 & Risk Compensation & 9 & D30 & Supervision & 3 \\
\hline D15 & Talent Cultivation & 9 & D31 & Technology Equity Investment & 2 \\
\hline D16 & Commercial Land Reform & 8 & & & \\
\hline
\end{tabular}

Table 2. Keywords co-word matrix (portion).

\begin{tabular}{|c|c|c|c|c|c|c|}
\hline Keywords & $\begin{array}{l}\text { Financial } \\
\text { subsidy }\end{array}$ & Qualification & $\begin{array}{l}\text { entrepreneurship } \\
\text { and employment }\end{array}$ & $\begin{array}{l}\text { achievement } \\
\text { transformation }\end{array}$ & $\begin{array}{l}\text { industry-university-research } \\
\text { cooperation }\end{array}$ & $\begin{array}{l}\text { financial } \\
\text { incentive }\end{array}$ \\
\hline Financial subsidy & 0 & 20 & 16 & 18 & 11 & 15 \\
\hline Qualification & 20 & 0 & 13 & 12 & 11 & 12 \\
\hline $\begin{array}{l}\text { entrepreneurship and } \\
\text { employment }\end{array}$ & 16 & 13 & 0 & 10 & 9 & 13 \\
\hline achievement transformation & 18 & 12 & 10 & 0 & 12 & 11 \\
\hline $\begin{array}{l}\text { industry-university-research } \\
\text { cooperation }\end{array}$ & 11 & 11 & 9 & 12 & 0 & 9 \\
\hline financial incentive & 15 & 12 & 13 & 11 & 9 & 0 \\
\hline
\end{tabular}

which will reduce accuracy to a certain extent. While The derived Ochiai coefficient assumes that when the number of co-occurrences between pairs of words is zero, there is no similarity between word pairs, which is not in accordance with the actual situation. In this paper, Cosine similarity is used to measure the correlation between word pairs, and the similarity matrix of keywords is obtained. Some results are shown in Table 3.

\subsection{Multidimensional Scaling Analysis}

Using the SPSS 19.0 statistical software, the similarity matrix of the keywords of incubator policy is analyzed by a multi-dimensional scale (PROSCAL), and the 
Table 3. Keywords similarity a atrix (portion).

\begin{tabular}{|c|c|c|c|c|c|c|}
\hline Keywords & $\begin{array}{l}\text { Financial } \\
\text { subsidy }\end{array}$ & Qualification & $\begin{array}{l}\text { entrepreneurship and } \\
\text { employment }\end{array}$ & $\begin{array}{l}\text { achievement } \\
\text { transformation }\end{array}$ & $\begin{array}{l}\text { industry-university-research } \\
\text { cooperation }\end{array}$ & $\begin{array}{l}\text { financial } \\
\text { incentive }\end{array}$ \\
\hline Financial subsidy & 1.000 & 0.796 & 0.842 & 0.790 & 0.877 & 0.834 \\
\hline Qualification & 0.796 & 1.000 & 0.888 & 0.889 & 0.863 & 0.874 \\
\hline $\begin{array}{l}\text { entrepreneurship and } \\
\text { employment }\end{array}$ & 0.842 & 0.888 & 1.000 & 0.904 & 0.890 & 0.851 \\
\hline achievement transformation & 0.790 & 0.889 & 0.904 & 1.000 & 0.837 & 0.888 \\
\hline $\begin{array}{l}\text { industry-university-research } \\
\text { cooperation }\end{array}$ & 0.877 & 0.863 & 0.890 & 0.837 & 1.000 & 0.890 \\
\hline financial incentive & 0.834 & 0.874 & 0.851 & 0.888 & 0.890 & 1.000 \\
\hline
\end{tabular}

corresponding visualization results are obtained as shown in Figure 1. Stress = 0.18890 is less than 0.2 and RSQ $=0.90735$ is greater than 0.8 in multidimensional scaling analysis, so the result is credible.

\subsection{Connotation Analysis of Policy Main Group}

In theory, the distribution of key words in the results of multidimensional scaling analysis shows that the key words appear in the policy text at the same time, that is, collinearity. Highly colinear keywords are gathered together to form a main group with high Relevance. The distance between the groups is determined by the number of co-occurrence keywords and the co-occurrence frequency between the groups. The closer the subject group is to the origin, the more important the subject group containing the greater number of keywords. [14]

According to the results of multidimensional scaling analysis and the classification of the policy tools and contents represented by the keywords, the high-frequency keywords of the incubator policy can be divided into four main groups, and each main group has a theme, just as shown in Figure 1, A1 is land support group, A2 is taxation group, A3 is financial support group, and c group. The key words covered by different subject groups are shown in Table 4. Among them, the A3 financial support group contains the largest number of keywords, the distance from the origin closest and occupies the core position, is the most important main group, the other three main groups relatively independent, far from the origin.

A1 is land use subject group, reflecting that government provide various channels for incubator land supply support, including government land arrangement plan, industrial and commercial land reform and "three old" transformation. All of those help the development of incubators from the source of incubator construction land. In addition, the government of Guangdong province introduced the system of property separating, which is the first time in China. The policy, "Guangdong Provincial People's Government on accelerating scientific and technological innovation on a number of policy advice" pointed out that "under the premise of not changing the use of incubation services for science and technology enterprises, the technology-based business incubators for 


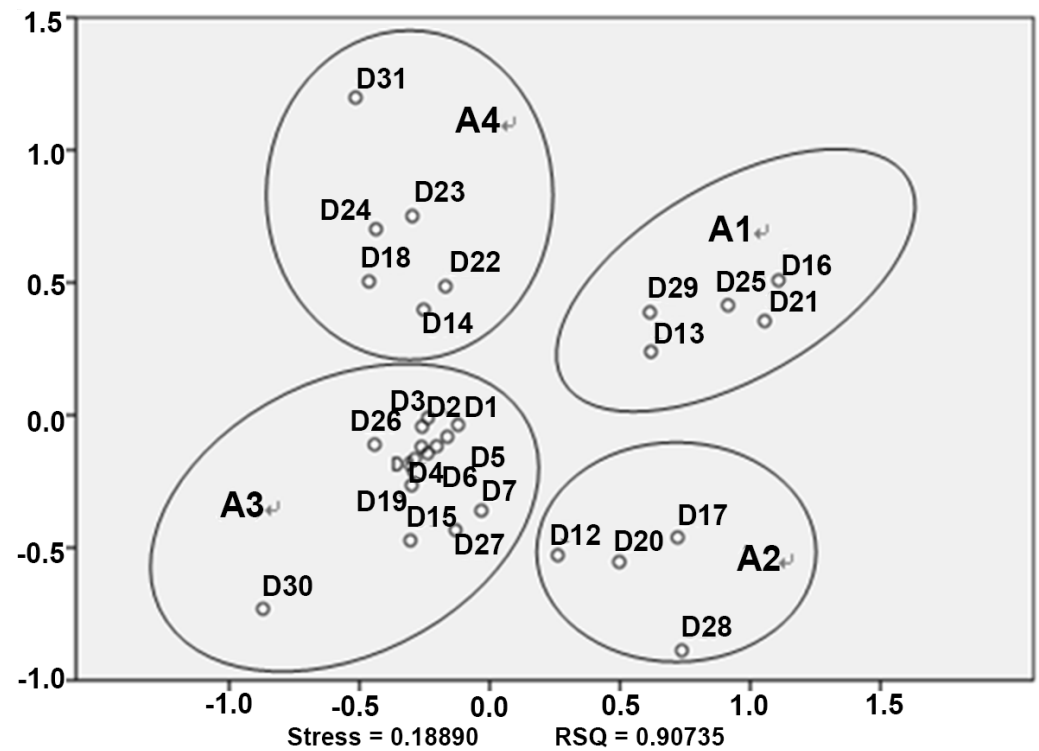

Figure 1. Keywords multidimensional scaling analysis.

Table 4. Four subject groups and labels.

\begin{tabular}{|c|c|}
\hline Subject Group & Keywords \\
\hline $\begin{array}{c}\text { A1 } \\
\text { Land Support }\end{array}$ & $\begin{array}{l}\text { Land Use Planning Commercial Land Reform Industrial Land Reform } \\
\text { "Three Old" Transformation Property Separating }\end{array}$ \\
\hline $\begin{array}{c}\text { A2 } \\
\text { Taxation }\end{array}$ & $\begin{array}{l}\text { Tax Preference Rent Reduction R\&D Costs Deduction Accelerate } \\
\text { Depreciation }\end{array}$ \\
\hline $\begin{array}{c}\text { A3 } \\
\text { Financial Support }\end{array}$ & $\begin{array}{l}\text { Financial Subsidy Qualification Entrepreneurship and Employment } \\
\text { Achievement Transformation Industry-university-research Cooperation } \\
\text { Financial Incentive Post-subsidy Scientific and Technological Innovation } \\
\text { Special Funds Demonstration Base Performance Evaluation Talent } \\
\text { Cultivation Service Platform Infrastructure Construction Supervision } \\
\text { Government Purchases }\end{array}$ \\
\hline $\begin{array}{c}\mathrm{A} 4 \\
\text { Investment and } \\
\text { Financing Support }\end{array}$ & $\begin{array}{l}\text { Risk Compensation Financing Support Public Crowd funding Loan Discount } \\
\text { Angel Investment Technology Equity Investment }\end{array}$ \\
\hline
\end{tabular}

industrial land use can be registered and leased or transferred according to the fixed units such as buildings and floors as the basic units."

A2 is tax policies subject group, tax preference categories include business tax, enterprise income tax, property tax and urban land use tax, besides R\&D instruments and equipment in incubators can enjoy accelerated depreciation policy. At the same time, the incubator tax policy is also reflected in the tax support for enterprises in hatch, in order to encourage entrepreneurship-employment and enterprises to carry out research and development innovation, government provides and amount of rent relief, R\&D deductions and other tax incentives for start-ups in a certain range and time to support and help start-ups grow and develop and guide enterprises to carry out scientific and technological innovation activities. 
A3 is financial support subject group, and is closest to the origin and contains the largest number of keywords, indicating that financial support is the primary policy support for incubator support policies. Through combing, it is found that the ways of financial support for incubators mainly include the following: first, financial subsidies are given to newly build incubator or proportion, "Some Opinions of Guangdong Provincial People's Government on Accelerating Scientific and Technological Innovation" states that "the incubator operating agencies will get the prefecture-level financial subsidies for newly added hatching area, in the same time provincial finance will also be given no higher than half the proportion of subsidies in the city subsidies for them. "Second, government will subsidize financial incentives to high performance incubators through operational performance evaluation. Third, government will evaluate incubators to determine the level, the results followed by national, provincial, municipal incubators or business demonstration bases, access to different amounts of financial capital awards.

Fourth, government encourages eligible incubators to apply for special fund or fund support, including special fund for employment in start-ups, special funds for construction of service platforms for small and medium-sized or micro-enterprises, special funds for technological innovation, special funds for industrialization of achievements, venture guiding funds and so on.

A4 is investment and financing support subject group, and the distance from the origin is also relatively close, which means that investment and financing support is the other focus of incubator support policy. Guangdong Province has set up a credit and risk compensation system for business incubators, encouraged venture capital institutions and social capital to set up venture capital funds for small and medium-sized or micro-enterprises in incubators to support financial institutions in providing loans for those enterprises and promote the conversion of scientific and technological achievements industrialization. In February 2015, "Trial Provisions on Venture Capital and Credit Risk Compensation Funds for Business Incubators" clearly stated that the role of venture capital and credit risk compensation funds was to "give compensation to the failure of venture capital in incubators or bad debts emergence of the first loan in hatched enterprises according to a certain percentage of compensation ", and to make provisions for risk compensation standards. All those methods want to support and solve financing difficulties in incubated enterprises.

\section{Conclusions and Recommendations}

\subsection{Research Conclusions}

Through the multi-dimensional scale analysis of keywords of the sample policy text, combined with the analysis results, the following conclusions can be drawn:

First, the incubator policy in Guangdong Province is an organic integration of various policies covering many aspects such as incubator construction and operation management and so on. According to the result of clustering, the overall 
policy of incubator in Guangdong is mainly composed of four types of policies: Land support, taxation, financial support, investment and financing policies. These polices, formed by clustering a single key word in the policy text, are rooted in the current policy and accurately reflect the structural characteristics of the current policy.

Second, the financial support is the core of the incubator policy in Guangdong. It appears frequently in the policy system and is located in the middle of the multi-scale analysis diagram. It is the most important policy theme to promote the incubator construction. The financial input is the main way to support the development of incubators, from this we can know that at this stage, the development of incubator is still in a relatively early stage and its primary form needs to rely on the government's financial input to support its construction and operation. Tax relief is another way to reduce the burden on incubators, but tax policy covers the least keywords, which means tax incentives are limited. Through the thorough reading of the policy, we find that at the tax level, Guangdong Province still implements the national tax policy on incubators mainly; the tax incentives at the provincial level are less innovative ways.

Third, investment and financing policies have become the independent theme of incubator policy support, covering risk compensation, discount interest loans and public crowdfunding and so on. Although the investment and financing policies are not the most important aspects of Guangdong's incubator policy and the number of keywords involved are limited, from the existing keywords and clustering results, we know that government has already started to promote advanced service capabilities such as investment and financing of incubators and encourage the participation of social forces and promote the social capital into the development of incubators and incubating enterprises.

Last, Guangdong provincial government gives strong support to the construction site of incubators. In addition to the planned land use by the government, it is permitted and encouraged to transform many types of sites into incubators, including industrial and commercial sites, as well as "three old" transformation, which from the land source to ensure the construction and development of incubators and also reflects the fact that the government still remains concerned about the increase in the number of incubators.

\subsection{Policy Recommendations}

Based on the above research and conclusions, this paper proposes the following policy suggestions:

Continue to improve the support from the entire chain of incubator construction, operation and service, shift from focusing on quantity growth to focusing on improving the service capability of incubators. At present, most of Guangdong's incubator policies still focus on the incubator construction level, focusing on the front of the incubator development chain and have achieved great success. Guangdong's incubator has ranked first in the country. But the mere quantitative development is far from enough. The function of incubator is to effec- 
tively promote the innovation of science and technology and the transformation of scientific and technological achievements so as to provide support and help to start-ups. The social benefit that incubators can bring is the ultimate goal of incubators. Therefore, when the number of incubators is growing rapidly, policies should shift to the middle and back-end of the incubator's service chain, that is, to guide and support incubators to enhance their service capabilities, especially their investment and financing capabilities.

Change the mode of financial support and implement the post-subsidy mode based on performance or achievements as the assessment standard, and create a good development environment for incubator as the policy's main concept. According to the analysis, we can see that financial support is the core of Guangdong's incubator policy. The Guangdong provincial government has invested a lot of money in rewarding subsidy incubators directly. However, this method may cause incubators to rely on government subsidies for profits, while its own "hematopoietic" mechanism is missing, when they lose subsidies, they may unsustainable and barely survive, which lose the purpose and significance of government encouragement and support. Therefore, we should change the mode of support, using result-oriented as the standard of support, such as post-subsidy, achievement subsidy, taxation and other policy means.

Strengthen personnel support and improve regulatory measures. The operation of incubators and the provision of incubator services all require specialized and high-level personnel. However, it can be seen from the above that there are few supportive policies for talents in the keyword of incubator policies, therefore, government needs to vigorously develop incubator talent strategy to ensure and protect the development of incubator. At the same time, higher education courses about incubating service personnel should be carry out to realize the specialization of incubating qualified personnel. In the aspect of supervision and management, the supervision on financial subsidies, land use are relatively weak or even non-supervisory. As a result, the subsidies can not be used to the actual operation and construction of incubators, land is occupaied but not used for its actual purpose or other phenomena occur. Therefore, the policy needs to implement the rights and responsibilities of all parties to promote the government, incubators and social forces to work together to create a good atmosphere and conditions for the development of incubators.

\section{References}

[1] Wu, S.R., Li, Z. and Wang, R. (2003) Comparative Study of Business Incubators in China, America, France and South Korea. Shanghai Economic Review, No. 2, $11-18+53$.

[2] Qu, Q.Z. (2005) The Chinese and Foreign Business Incubation Advances Research and Enlightens to China. Scientific Management Research, No. 5, 119-122.

[3] Sun, D. and Zhou, Y.J. (2013) Research on the Status and Development Strategy of Business Incubator-Based on the Special Audit Survey of the Incubator Construction and Operation in Nanjing. Science \& Technology Progress and Policy, No. 18, 
120-123.

[4] Shi, Y.F. (2010) Government Incentives and Policy Innovations in Business Incubators-A Case Study of Hangzhou. Science \& Technology Progress and Policy, No. 14, 103-107.

[5] Chen, Y. and Cui, J.J. (2016) Evaluation of the Conduction Effect of Incubator Tax Incentive. Science Research Management, No. 3, 101-109.

[6] Law, J., Bauin, S., Courtial, J.P., et al. (1988) Policy and the Mapping of Scientific change: A Co-Word Analysis of Research into Environmental Acidification. Scientometrics, 14, 251-264. https://doi.org/10.1007/BF02020078

[7] Su, J.Q., Li, X.A. and Xu, X.A. (2012) Comparative Analysis on Technology Innovation Policy of State and Local Based on Content Analysis. Science of Science and Management of S\&T, 33, 15-21.

[8] Liu, F.C. and Sun, Y.T. (2007) The Course of, Trend in and Proposal for Evolution from S\&T Policies to Innovation Policies-Based on the Empirical Analysis of China's 289 Innovation policy Documents. China Soft Science, No. 5, 34-42.

[9] Peng, J.S., Zhong, W.G. and sun, W.X. (2008) Policy Measurement, Policy Coordination Evolution and Economic Performance: An Empirical Study Based on Innovation Policy. Management World, No. 9, 25-36.

[10] Huang, C., Su, J., Shi, L.P. and Cheng, X.T. (2011) Textual and Quantitative Research on Chinese Wind Energy Policy System from the Perspective of Policy Tools. Studies in Science of Science, No. 6, 876-882+889.

[11] Liu, F., Simon, D.F., Sun, Y., et al. (2011) China's Innovation Policies: Evolution, Institutional Structure, and Trajectory. Research Policy, 40, 917-931. https://doi.org/10.1016/j.respol.2011.05.005

[12] Rothwell, R. and Zegveld, W. (1981) Industrial Innovation and Public Policy: Preparing for the 1980s and 1990s. Frances Printer, London, 10-12

[13] Courtial, J.P. (1994) A Coword Analysis of Scientometrics. Scientometrics, 31, 251-260. https://doi.org/10.1007/BF02016875

[14] Luo, M. and Zhu, X.Z. (2014) Co-Word Analysis on Low-Carbon Policies Frame in China. Chinese Journal of Management, 11, 1680-1685. 